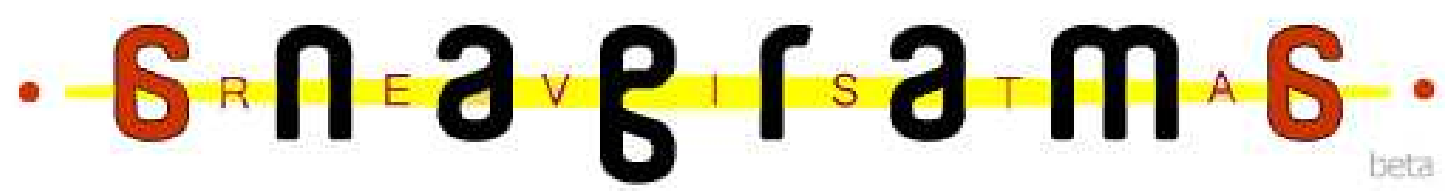

\section{A História da Ficção Pulp em Planetary:}

\section{Metalinguística Crítica para a manutenção de um Mundo Estranho}

\section{Tiago Abreu חogueira ${ }^{1}$}

\section{Resumo}

Nos últimos anos do século XX o selo Wildstorm da editora norte-americana DC Comics lançava as primeiras edições de Planetary, uma série de Histórias em Quadrinhos que acompanhava as aventuras de personagens auto-intitulados "arqueólogos do impossível". O presente artigo objetiva analisar uma faceta específica da obra, sob o jugo e rigor que uma pesquisa histórica exige: Planetary trabalha principalmente com o uso de referências, recurso muito comum à arte contemporânea, mas faz isso construindo um teor crítico e auto-crítico à sua(s) metáfora(s), de modo que o dialogismo que se forma a partir do desenrolar da série é capaz de abraçar esferas muito mais amplas que as normalmente tratadas em quadrinhos de super-heróis.

Palauras-chaue: HQs; Planetary; Metalinguagem; Pulp Fiction.

"Warren Ellis e John Cassaday fabricaram um engenhoso mecanismo com a ajuda do qual podem explorar as possibilidade da nossa situação contemporânea. Os heróis do conto deles não são combatentes do crime, nem guardiões globais, mas, por conta de algum perfeito acesso de inspiração, são arqueólogos. Pessoas escavando sob a superfície do mundo para descobrir seu passado, seus segredos e suas maravilhas. Nesse caso, entretanto, o mundo que está sob a escavação não é nossa esfera imediata, embora seja tão familiar quanto. Ao invés disso, abrimos passagens para um planeta que não é nada mais do que a paisagem acumulada de quase uma centena de anos de fantasia e de histórias em quadrinhos" - Alan Moore, na introdução do primeiro volume encadernado de Planetary.

Nos últimos anos do século XX o selo Wildstorm da editora norte-americana $D C$ Comics lançava as primeiras edições de Planetary, uma série de Histórias em Quadrinhos que acompanhava as aventuras de personagens auto-intitulados "arqueólogos do

\footnotetext{
${ }^{1}$ Estudante da Universidade Anhembi-Morumbi. Artigo apresentado à Pró-reitoria Acadêmica fruto de um ano de Pesquisa pelo Programa de Iniciação Científica da Anhembi Morumbi 2010/2011, e orientado pela Professora Dra. Inez Pereira da Luz.
} 
impossível". Originalmente programada como uma série de vinte e quatro edições bimestrais, Planetary sofreu longos atrasos e após alguns hiatos em sua publicação, atingiu a conclusão da obra em 2009, totalizando vinte e sete edições de vinte e duas páginas, mais um preview de oito páginas e três crossovers de quarenta e oito, tudo isso parcialmente publicado no Brasil em duas edições encadernadas da editora Devir e revistas periódicas da editora Pixel Media.

Planetary apresenta um tipo de ficção científica estranha mesmo para os padrões das histórias em quadrinhos, em especial das comics norte-americanas de super-heróis (que compõe majoritariamente o fluxo editorial da $D C$ Comics). Sua linguagem é singularmente mais madura e os assuntos tratados são aprofundados ao extremo e relativamente amarrados a cada edição, de modo que cada capítulo da macro-trama possa ser minimamente auto-explicativo ao leitor em sua unidade. Seu poder de síntese é espantoso. Síntese particularmente expressa em toda a obra dos autores, o roteirista Warren Ellis e o brilhante desenhista John Cassaday.

O presente artigo objetiva analisar uma faceta específica da obra, sob o jugo e rigor que uma pesquisa histórica (por que não dizer arqueológica?) exige: Planetary trabalha principalmente com o uso de referências, recurso muito comum à arte contemporânea, mas faz isso construindo um teor crítico e auto-crítico à sua(s) metáfora(s), de modo que o dialogismo que se forma a partir do desenrolar da série é capaz de abraçar esferas muito mais amplas que as normalmente tratadas em quadrinhos de super-heróis.

Ao fim, do ponto de vista histórico e cultural, a série é capaz de reunir um compêndio realmente historiográfico acerca do próprio gênero da ficção científica, partindo de suas raízes na literatura oitocentista de Julio Verne, passando pelo Pulp Fiction das primeiras décadas do século XX, tão inspirado pela Guerra Fria e pelo Terror Nuclear, até os conceitos tecnológicos mais vanguardistas que despontavam durante o advento da literatura cyberpunk oitentista, como a nanotecnologia, a internet, a interatividade, o espaço virtual, a engenharia genética, o surgimento da bioética como ciência e filosofia e tantos outros.

Planetary, afinal, é sobre o século XX. Sobre como esse século se transformou mais que qualquer outro anterior. Sobre como esse século mudaria tudo, enfim. No fio da navalha entre um otimismo inspirado e iconoclasta e um niilismo próprio, inclusive, do século XX, Planetary fala de transformações históricas pela transformação da arte e sugere o vice-versa dessa equação à medida que soma eloqüência ao seu discurso narrativo. E essa 
eloquência, segundo nossa hipótese, é assegurada pelo uso bem sucedido das metáforas, do uso de uma linguagem simbólica, e ainda, um uso consciente de todo um leque semiótico de ícones, símbolos e signos próprios da arte sequencial para formular e fortalecer as metáforas responsáveis pela associação de significados que, por sua vez, garantirá ao leitor a possibilidade de escavar níveis de compreensão e reconhecimento na obra. Planetary é como um livro pop-up ao avesso, onde a ação de sua narrativa não pula da página tal qual dobradura, mas está enterrada em suas entranhas, sob a página, em algum lugar entre a arte estonteante e o enredo vertiginoso.

Essa dinâmica narrativa é particularmente interessante porque trata da obra não do ponto de vista do que ela é, enquanto fato histórico consumado ou material publicado, mas enquanto possibilidade. Algo que garante ao leitor a possibilidade de aproximar-se da obra, de seus personagens e até dos autores em si por meio de uma ação interpretativa mais assertiva, autônoma e inclusive criativa também. O leitor é retirado da zona de conforto do mero expectador e convidado a interagir intelectualmente com a obra. Esse mergulho interpretativo já foi tema e objeto de estudo para diversos autores que teorizaram sobre arte contemporânea, cinema, televisão, teatro, curadoria... Em especial, Umberto Eco nos guiará por essa jornada caleidoscópica e hiper-referencial. Eco apresenta, sobretudo em seus ensaios, pistas fundamentais para a compreensão da relação leitor-autor estabelecida no formato seriado de narrativa. Mas já que parte substancial da pauta é justamente a hiperreferência, vejamos o que nos diz sobre Umberto Eco, outros estudiosos que também participam dessa ciranda de interpretação e estudo das artes, como Erika Sevrini, que comenta Eco em Obra Aberta, no capítulo Da Materialidade e Abertura da Obra, de seu livro Índice de um Cinema de Poesia:

No livro Obra Aberta, que reúne textos escritos na segunda metade de 1960, Umberto Eco propõe como questão central no estudo da arte contemporânea a dialética entre a materialidade da obra e a abertura, de modo a conjugar sua integridade física com uma pluralidade interpretativa. Para tanto, elabora o seguinte conceito de obra de arte: '...um objeto dotado de propriedades estruturais definidas, que permitam, mas coordenem, o revezamento das interpretações, o deslocar-se das perspectivas.' Eco. Obra Aberta.

A abertura não é um fenômeno recente, faz parte determinante do conceito de arte. $\mathrm{O}$ diferencial é que, na contemporaneidade, a abertura se transforma em um "programa de produção". Ciente das propriedades do texto (entendido como toda obra de arte), o artista prevê o leitor como uma instância de concretização, isto é, a interpretação é aceita como integrante da estratégia criativa. Nesse esquema, a obra torna-se o centro da análise, de onde se vislumbra o seu "autor-modelo" e o seu "leitor-modelo" segundo a "intenção do texto".

O texto é entendido como uma complexa rede sígnica, cuja codificação, decodificação e interpretação escapam ao controle absoluto do indivíduo que o gerou, chamado de "autor-empírico". O "autor-modelo" é a entidade abstrata responsável pela codificação 
em seus detalhes e que, portanto, possui conhecimento das interpretações possíveis. $\mathrm{O}$ indivíduo que usufrui o texto (o seu "leitor-empírico") possui a limitação de seu repertório, do momento histórico em que vive (mais ou menos divergente com o da produção de texto) ou de fatores emocionais, que lhe impõem obstáculos à apreensão ideal da obra. O texto foi elaborado visando uma decodificação e interpretação plenas por parte de um "leitor-modelo" capaz de atualizar a rede sígnica elaborada pelo autormodelo, constituindo-se este também como uma entidade abstrata e hipotética, uma estratégia criativa.

Eco salienta que existem limites para a interpretação. O estudioso deve tentar selecionar o que está presente como intenção do texto e o que representa apenas projeções da sua subjetividade como leitor sobre a obra. $O$ texto é a origem e o objetivo do estudo e deve-se respeitar o que efetivamente ele permite de liberdade, se deseja-se pesquisar os seus mecanismos lingüísticos (Sevrini, 2004).

Então, aquele que reconhece em Ao Redor do Mundo, na primeira edição de Planetary, na figura da personagem Axel Brass, uma referência a Flash Gordon, e aos seus heróis associados uma referência aos primeiros personagens das pulp magazines das primeiras décadas do século XX, como Spider, Shadow, Fu Manchu, Tarzan e tantos outros, certamente reconhecer-se-á como protagonista do enredo apresentado, uma vez que trata-se de uma imensa trama de mistério e investigação dessa linha referencial e esses conhecimentos serão certamente valorizados para os futuros desvendares. Mas ainda assim, aquele leitor que não fizer esse reconhecimento imediato poderá ser conduzido a ele pelo próprio desenrolar do argumento, e em ambos os "tipos" de leitor, ficará a possibilidade de interpretar dessa referência às pulp magazines uma crítica sobre a forma como os quadrinhos de super-heróis fagocitaram de maneira quase predatória a produção popular de ficção científica de baixo custo, gradativamente substituindo-a pelo atual mercado pop de comics.

Logo na primeira edição já apresenta-se o conceito de complexo de universos unidos à sangria - o espaço entre realidades - como células unidas pelo plasma na corrente sanguínea, não necessariamente paralelos, mas interligados como as arestas de um floco de neve, possibilitando cruzamentos que podem ser milagrosos ou apocalípticos. Esses universos paralelos que se cruzam representam a intertextualidade em si, enquanto a ação das personagens e sua relação com o entendimento do leitor formam uma representação da própria polifonia, que injetará nova vida aos ecos já quietos do que foi a ficção esquecida por um tempo cuja hiperinformação transforma algumas décadas atrás em eras ancestrais hiperboreanas. Desde a internet, ontem é pré-história.

Por isso consideramos a metalinguagem fator central dessa construção dialética e buscamos entendê-la enquanto técnica e enquanto fenômeno linguístico: 
A metalinguagem permite que o público experimente, ainda que de forma imaginária, do processo de construção da narrativa. Dessa forma, a utilização deste recurso propicia um 'jogo' mais aberto e, de certa forma, mais democrático com o espectador - uma vez que explicita suas próprias regras. Segundo Umberto Eco, 'O prazer do leitor consiste em encontrar-se mergulhado em um jogo do qual se conhecem as peças e as regras, e mesmo o desfecho fora algumas variações mínimas (Eco, 1976, p.158).

Talvez pareça a um primeiro olhar que para o leitor, conhecer "as peças $e$ as regras (...) e mesmo o desfecho" do jogo possa reforçar sua imobilidade na zona de conforto da expectativa, mas no caso de Planetary, é exatamente o oposto que ocorre. Ao invés de esperar/expectar/imergir nas referências oferecidas pela metalinguagem, o leitor engaja-se em mergulhar mais do que uma primeira leitura superficial possa imediatamente oferecer, afim de interpretar as referências ocultas sob as explícitas.

Planetary oferece essa possibilidade porque suas metáforas trazem, além das referências internas de gênero, críticas diretas aos meios de produção e perfis editoriais... afinal, não é sem propósito que os quatro algozes e antagonistas dos protagonistas de Planetary fazem referência direta ao Quarteto Fantástico, possivelmente as personagens mais emblemáticas da clássica produção da Marvel Comics, editora que é concorrente direta da DC (que encampa a produção de Planetary) e é notória por campanhas publicitárias agressivas e inúmeros processos judiciais de plágio e apropriação indevida de personagens.

Retomo as palavras de Haroldo de Campos, que em seu ensaio Comunicação na Poesia de Vanguarda nos diz que "A função metalinguística pode ocorrer também em coligação com o exercício da própria função poética, em poemas ou textos criativos que envolvem uma crítica do próprio ato de escrever." Ou seja, para além da referência, há um tom, há uma linha crítica, uma interpretação muito própria dos autores da série sobre como as séries em quadrinhos são feitas, sobre como os artistas são tratados, sobre como negócio e arte podem macular estruturalmente ambos os fenômenos e culminar em algo que possa ser edificante para ambos os lados.

Mas Warren Ellis e seus comparsas não querem ser "edificantes para ambos os lados" eles querem ferir os injustos e punis os corruptos e denunciar os desonestos e ridicularizar os acomodados. Nisso o uso da metalinguagem crítica de Planetary é singular entre as comics, sobretudo as de super-heróis: A crítica afiada, tenaz, contundente, implacável e por vezes ácida e indigesta que Ellis costuma conferir às suas obras não limita-se à crítica de quadrinhos, da produção editorial, ou "de arte", mas é evocação de 
uma visão crítica de mundo, que trata de apontar os aspectos mais detestáveis da vida humana cotidiana, acusando machismo, racismo, vício, corrupção, preconceitos diversos e os próprios processos de exploração do trabalho e dominação cultural no desenrolar de seus enredos sobre naves espaciais e monstruosidades.

Tomemos por exemplo a segunda edição, $A$ Ilha, na qual a referência direta são os monstros gigantes japoneses tão populares em seriados de TV das décadas de setenta, oitenta e noventa. Muito provavelmente o primeiro foi Godzila, personagem que já metaforizava o potencial destrutivo da ciência nuclear encontrando-se com as forças da natureza, mas posteriormente o "monstro gigante" tornou-se extremamente popular e sua "fórmula narrativa" foi repetida à exaustão por séries correlatas tais quais Ultraman, Jaspion, Changeman, Espectroman e tantas outras. Em seu formato original, normalmente o monstro gigante representa uma força de caos, originado do encontro entre natureza e radiação ou energia nuclear, ilustrando a ameaça de uma força fora de controle e incontrolável... exceto pelo herói, que valendo-se de representações da tecnologia, normalmente robôs gigantes que se montam a partir de veículos ou maquinários gigantes, é capaz de conter a ameaça e devolver ordem à vida urbana cotidiana. Uma vida cotidiana regada a altas doses de disciplina e relações de obediência e exploração social.

Nota-se claramente que o estrutura psicológica dessa narrativa original já possibilita uma infinidade de possibilidades interpretativas, mas atemo-nos a versão do tema abordada em Planetary \#2:

A ilha que dá título à edição é uma espécie de santuário onde esses monstros gigantes um dia foram para morrer, algo como um cemitério de elefantes. Mas essa ilha é invadida por um grupo de japoneses liderados por um escritor psicopata, em alusão direta às trágicas seitas ou células terroristas como a Aum Shinrikyo, que numa mistura de carisma e fanatismo religioso levou tantas pessoas à morte. Podemos afirmar que na edição reservada para discutir o tema "monstros e monstruosidade", os tais monstros gigantes são tão somente o cenário no qual a monstruosidade humana (tão tipicamente humana) irá desenrolar-se em toda sua crueldade potencial. E essa crueldade monstruosa não é tão bem caracterizada porque o vilão é particularmente cruel e monstruoso, mas porque sua crueldade é abastecida de características corriqueiras da vida pós-moderna, quiçá humana em geral, como egocentrismo, megalomania, vaidade, soberba. O autor faz sua crítica aproximando o monstro do leitor, não como se mostrasse o primeiro ao segundo, mas como se retirasse uma amostra do segundo e exibisse o que ela tem de comum com a 
natureza do primeiro. E os monstros gigantes, afinal, tornam-se belos fenômenos da natureza, como um animal em extinção, puro, imaculado e sublime ante a baixeza da alma humana.

Por isso tivemos entre nossos objetivos específicos da pesquisa interpretar o uso crítico da metalingüística em Planetary, ou seja, analisar como a metalinguiística torna-se veículo de criticismo na obra em questão. Notamos que isso está presente em toda a obra e que a potencialidade de aprofundamento, aliada a uma abordagem cíclica dos temas e referências, é sempre crescente e praticamente ilimitada, pois expande-se para além da arte, abarcando ciência, política, cultura, religião...

Fica-nos muito claro através desse exemplo que Warren Ellis considera o protagonismo do inventário imagético do seu leitor como ferramenta de evocação não somente de um conhecimento de textos, mas de um conhecimento do mundo teorizado por Umberto Eco no conceito de enciclopédia intertextual, que nos diz:

Temos textos que citam outros textos, e o conhecimento dos textos anteriores é pressuposto necessário para a antecipação do texto em exame. Para uma leitura mais completa de uma obra, ou mesmo para a identificação e o reconhecimento das citações intertextuais, o expectador necessita a priori de um amplo inventário como referencial para que se constitua de forma mais eloquente e funcional. (ECO, 1989, p.127).

Por isso esse artigo também não se predispõe a analisar sistematicamente cada uma ou um apanhado específico de edições de Planetary, porque pressupõe que suas possibilidades interpretativas são ilimitadas e qualquer tentativa de contê-las num compendium soaria pretensiosa e despropositada. Ao invés disso, convidamos a observar como essa narrativa não encerra pontos de fuga bidimensionais e de que forma algo pode ir e voltar de universos diferentes a partir de uma simples inversão de perspectiva. Seus objetivos, explicitados pelo protagonista Elijah Snow em Planetary \#26, já são por si só interessantes:

"A vida é repleta de sistemas de proteção. Todos muito complexos. É um mistério. Foram precisos anos de trabalho pra limpar a crosta protetora e vê-los pelo que são de verdade. Sistemas criados pelo próprio núcleo de realidade. Você escava, exuma e se afasta até finalmente encontrar um padrão.” - Warren Ellis, Planetary \#26

E não é disso que se trata qualquer trabalho intelectual? Qualquer produção escrita? A leitura em seu sentido mais radical? É certo que quando citam os "sistemas de proteção" muito provavelmente há uma referência ao sistema de direitos autorais que se 
interpõem entre o artista, a obra e os donos de seus direitos de publicação, e em diversos momentos da série, os autores desafiaram esse sistema valendo-se de inteligência e semiótica para apropriarem-se livremente, com notável perícia e impunidade, de diversas personagens e histórias de diversas editoras e corporações da indústria cultural, dentre elas algumas das mais conservadoras e sectárias com relação a compartilhamento de conhecimento e material artístico, como a supracitada Marvel Comics, para citar apenas uma.

Um autor com objetivos tão ambiciosos e um leque de referências tão vasto acabaria por tornar-se ele próprio uma personagem: outra vez, nada de novo no mundo da ficção, onde autores tornam-se tão ou mais míticos que suas personagens, mas segundo ele próprio explica em edição muito anterior à supracitada, suas intenções estão tão acessíveis e claras quanto as referências que utiliza e seu maior mérito está em aliar aprofundamento com aproximação ao passo que a superficialidade relega o saber ao distanciamento desse da interpretação prática que possa haver na e da vida, objeto e obra máxima de apreciação:

\begin{abstract}
"Nós temos uma relação estranha com nossa ficção, entende? Ás vezes tememos que ela esteja nos dominando. Outras vezes imploramos para que ela nos domine... Algumas vezes queremos ver o que há por dentro dela. Esse era o perfil inicial do projeto: criar um mundo fictício e depois pousar nele. Uma missão para recolher amostras. Trazer alguém de uma realidade fictícia." - Warren Ellis, Planeta Ficção, Planetary \#9
\end{abstract}

\title{
REFERÊTCIAS BIBLIOGRÁFICAS
}

ELLIS, Warren; CASSADAY, John. Planetary. Califórnia: Wildstorm, 1998 - 2009.

ELLIS, Warren; CASSADAY, John. Planetary. São Paulo: Editora Devir - 2005.

ELLIS, Warren; CASSADAY, John. Planetary. Rio de Janeiro: Pixel Media, 2008.

ECO, Umberto. Sobre os Espelhos e outros ensaios. Rio de Janeiro: Editora Nova Fronteira, 1985.

CAMPOS, Haroldo de. A arte no horizonte do provável. São Paulo, SP: Ed. Perspectiva, 1977. 
BARTHES, Roland ET AL. Análise Estrutural da Narrativa. Petrópolis: Vozes, 1976.

JAKOBSON, Roman. Linguística e comunicação. São Paulo, SP: Ed. Cultrix, 2001.

SEVRINI, Erika. Índices de um Cinema de Poesia Pier Paolo Pasolini, Luis Bunuel e Krzysztof Kieslovoski; Ed.UFMG, 2004.

ANDRADE, Ana Lúcia. O Filme Dentro do Filme - A metalinguagem no cinema; Editora UFMG, 1999.

FERNANDES, Rodrigo Emanoel. Planetary: Escavando a História Imaginária do SéculoXX, reflexões sobre espaços imaginários, cultura pop e história em quadrinhos, geradas no cotexto da disciplina de pós-graduação: Ficções do Real: Geografia das imagens, ministrada pelo prof. Wenceslao Machado de Oliveira jr. Programa de PósGraduação da Faculdade de Educação/UNICAMP. Publicado no site Reminiscências de um Lorde Velho, no link: http://lordevelho.blogspot.com.br/2010/05/planetary-escavandohistoria-imaginaria.html (Acessado em 28 de Março de 2012). 